\title{
The Identification of Prognostic Factors and Survival Statistics of Conventional Central Chondrosarcoma
}

\author{
Sjoerd P. F. T. Nota, ${ }^{1}$ Yvonne Braun, ${ }^{1}$ Joseph H. Schwab, ${ }^{1}$ \\ C. Niek van Dijk, ${ }^{2}$ and Jos A. M. Bramer ${ }^{2}$ \\ ${ }^{1}$ Orthopaedic Oncology Service, Massachusetts General Hospital, Harvard Medical School, Boston, MA 02114, USA \\ ${ }^{2}$ Department of Orthopaedic Surgery, Academic Medical Center, 1105 AZ Amsterdam, Netherlands \\ Correspondence should be addressed to Sjoerd P. F. T. Nota; snota@mgh.harvard.edu
}

Received 17 June 2015; Revised 17 September 2015; Accepted 27 September 2015

Academic Editor: Manish Agarwal

Copyright (c) 2015 Sjoerd P. F. T. Nota et al. This is an open access article distributed under the Creative Commons Attribution License, which permits unrestricted use, distribution, and reproduction in any medium, provided the original work is properly cited.

\begin{abstract}
Introduction. Chondrosarcomas are malignant bone tumors that are characterized by the production of chondroid tissue. Since radiation therapy and chemotherapy have limited effect on chondrosarcoma, treatment of most patients depends on surgical resection. We conducted this study to identify independent predictive factors and survival characteristics for conventional central chondrosarcoma and dedifferentiated central chondrosarcoma. Methods. A systematic literature review was performed in September 2014 using the Pubmed, Embase, and Cochrane databases. Subsequent to a beforehand-composed selection procedure we included 13 studies, comprising a total of 1114 patients. Results. The prognosis of central chondrosarcoma is generally good for the histologically low-grade tumors. Prognosis for the high-grade chondrosarcoma and the dedifferentiated chondrosarcoma is poor with lower survival rates. Poor prognostic factors in conventional chondrosarcoma for overall survival are high-grade tumors and axial/pelvic tumor location. In dedifferentiated chondrosarcoma the percentage of dedifferentiated component has significant influence on disease-free survival. Conclusion. Despite the fact that there are multiple prognostic factors identified, as shown in this study, there is a need for prospective and comparative studies. The resulting knowledge about prognostic factors and survival can give direction in the development of better therapies. This could eventually lead to an evidence-based foundation for treating chondrosarcoma patients.
\end{abstract}

\section{Introduction}

Chondrosarcomas are malignant bone tumors that can be characterized by the production of chondroid tissue [1]. This heterogeneous group of tumors occupy about a quarter of all the primary malignant osseous neoplasms of the bone [2]. Chondrosarcomas are the most common occurring primary sarcoma of the bone after osteosarcoma $[2,3]$. The clinical behavior and prognosis of these tumors depend on many variables of which tumor grade is one of the most important; high-grade tumors have a worse prognosis compared to low-grade tumors $[4,5]$. This poor prognosis can partially be explained by the high tendency to metastasize. About three-quarters of all chondrosarcomas consist of conventional central chondrosarcoma. These central chondrosarcomas have the outgrowth of the sarcomatous tumor in the intramedullary cavity in common. The central chondrosarcoma's anatomical counterpart is the peripheral chondrosarcoma. These specific chondrosarcomas develop from a preexisting osteochondroma and are situated on the outside of the cortex of the bone. The peripheral chondrosarcoma tumors have a better prognosis when compared to the central chondrosarcoma and tend to affect younger patients [6].

Radiation therapy and chemotherapy have limited to arguably no effect on conventional chondrosarcoma $[7,8]$. There are rarer chondrosarcoma subtypes that are more responsive to chemotherapy and/or radiation therapy [9]. The vast majority of chondrosarcoma patients solely depended on the surgical treatment by tumor resection. Chemotherapy might have a role in dedifferentiated chondrosarcoma $[10,11]$ although the positive effect is not consistently reported in literature [11-13]. 
Identification of prognostic factors and knowledge about survival are important. For patients this knowledge can provide insight into their future perspective and it may provide guidance in the decision-making concerning treatment. Physicians can use the prognostic and survival information as a tool to select the optimal treatment strategy and inform patients. To direct efforts in the development of new therapeutic strategies the identification of proven prognostic factors of central chondrosarcoma is important, especially since the treatment options are limited. We conducted this systematic review with the aim of identifying independent predictive factors and survival characteristics for both conventional central chondrosarcoma and dedifferentiated central chondrosarcoma.

\section{Materials and Methods}

This systematic review was registered on PROSPERO prior to data extraction (registration number: CRD42014008961). The MOOSE checklist for meta-analysis of observational studies in epidemiology study was applied for the evaluation of metaanalysis and observational studies [14].

2.1. Search Strategy. We searched Pubmed, Embase, and the Cochrane database for title and abstract, without any limits on September 9, 2014, using the following search terms: (("chondrosarcoma*" OR "chondroid sarcoma” OR "chondroid sarcomas") AND “prognos*”) OR (("chondrosarcoma*" OR "chondroid sarcoma” OR "chondroid sarcomas") AND "surviv*") resulting in a total of 2253 publications.

\subsection{Study Selection, Data Extraction, and Critical Appraisal.} Two reviewers (Sjoerd P. F. T. Nota, Yvonne Braun) independently screened all the studies' titles and abstracts and retrieved the full-text manuscripts for the articles that met our inclusion criteria. If consensus was not reached between the two reviewers, a third reviewer (Jos A. M. Bramer) was consulted. We included all articles focusing on any prognostic factors and/or survival statistics on all grades (including dedifferentiated chondrosarcoma) of primary central chondrosarcoma of the bone.

We excluded congress proceedings, letter to the editors, cohorts that were not independently identifiable, all studies published in a different language than English, and studies published before 1980. In addition we excluded case-reports and case-series with less than 10 patients. Furthermore we excluded papers reporting on surgical procedures and studies focusing solely on metastasis. Finally we excluded all papers that did not clearly distinguish between central and peripheral chondrosarcoma and reviews were excluded as well.

After applying our exclusion criteria on the title and abstract 274 papers remained for full-text screening.

The quality of the data was assessed by application of predetermined critical appraisal criteria by two independent researchers. Lack of consensus was solved again as described above. The criteria assessed were as follows: study participation, study attrition, prognostic factor measurement, outcome measurement, confounding measurement, analysis performed, population included, the time of follow-up, the level of evidence, the presence of a disclosure statement, and the presence of a baseline characteristics table (Appendix).

2.3. Outcome Measurements. We extracted the data of the following variables from the selected studies: author/year, type of study, mean age, sex distribution, mean duration of follow-up, primary tumors only, metastasis at presentation, grading method, tumor grade, anatomical location, overall survival, and 5- and 10-year survival per grade. In addition we registered the disease-free survival, the percentage of patients with no evidence of disease, and the percentage of patients with no evidence of disease after tumor relapse. Furthermore we looked at the percentage of patients alive with disease and dead of disease and the percentage of patients that died of a different cause. We also looked at the local recurrence rate, the time to local recurrence, metastasis rate and time to metastasis, and the use of chemo- and radiation therapy. Finally to account for the homogeneity of the treatment of the patients in the studies we also reported the status of the surgical margins of the included subjects.

2.4. Analysis. To prevent reporting biased results due to the high quantity of cohort studies and case-series and potential overlap of patients' population we choose to only report our results narratively and did not attempt to merge results and do additional analyses.

2.5. Prognostic Factors and Survival Statistics. In this review we will narratively summarize the prognostic factors and survival statistics reported in our selected studies.

2.6. Study Characteristic. After screening the full-text articles we included 13 studies that met our inclusion criteria for this review $[10,15-26]$. The 13 studies included were based on retrospective evidence. All studies reported clearly the dates of researched period, the patient sample, and the point of the course of the disease. Nine out of the 13 studies (69\%) reported a sufficient long follow-up (more than 1 year) and explained the reason of patients being lost to follow-up. Four studies (31\%) did not report these factors and may therefore be subject to more selection bias (see the appendix).

2.7. Study Population. The 13 included studies comprised the data of 1114 patients, although population overlap is likely since multiple studies are performed in the same institution. In the studies where we could determine the age the average age of the patients ranged from 35 to 59 years and the percentage of males ranged from $42 \%$ to $79 \%$ with only 1 study reporting more females in the cohort. The mean followup ranged from at least more than 2 years to 13 years. The individual follow-up ranged from a minimum of 0 years to a maximum of 26 years (Table 1 ).

Not all studies mentioned the fact if only primary tumors and if recurrences were excluded or did included patient with such tumors (Table 2 ). There were a wide variety of tumor grades in the included studies. Three studies focused on central dedifferentiated chondrosarcoma and 1 study focused on grade 2 chondrosarcoma only; all other studies 
TABLE 1: Demographic patient and study characteristics of the included studies.

\begin{tabular}{|c|c|c|c|c|c|}
\hline Study & Study design & $\begin{array}{l}\text { Patients } \\
\text { (number) }\end{array}$ & $\begin{array}{c}\text { Mean age (range) } \\
\text { (years) }\end{array}$ & $\begin{array}{c}\text { Male } \\
(\%)\end{array}$ & $\begin{array}{c}\text { Follow-up (range) } \\
\text { (years) }\end{array}$ \\
\hline Andreou et al., 2011 [15] & $\mathrm{R}$ & 115 & $47(14-79)$ & $61 \%$ & $12(5-24)$ \\
\hline Angelini et al., 2012 [16] & $\mathrm{R}$ & 296 & $50(13-88)$ & $57 \%$ & $7(1.6-20)$ \\
\hline Briccoli et al., 2002 [17] & $\mathrm{R}$ & 14 & . & . & $5.8(0-19)$ \\
\hline Cho et al., 2011 [18] & $\mathrm{R}$ & 32 & . & $72 \%$ & $9.2(2.6-19)$ \\
\hline de Camargo et al., 2010 [19] & $\mathrm{R}$ & 46 & $43(17-79)$ & $54 \%$ & $8.3(2.7-26)$ \\
\hline Donati et al., 2010 [20] & $\mathrm{R}$ & 31 & $35(13-67)$ & $42 \%$ & $13(5.5-25)$ \\
\hline Donati et al., 2005 [21] & $\mathrm{R}$ & 63 & . & . & . \\
\hline Gitelis et al., 1981 [22] & $\mathrm{R}$ & 69 & $44(14-78)$ & $68 \%$ & $>5$ year \\
\hline Mavrogenis et al., 2013 [23] & $\mathrm{R}$ & 119 & . & . & $>2$ year \\
\hline Mitchell et al., 2000 [10] & $\mathrm{R}$ & 14 & $57(37-79)$ & $79 \%$ & $4.7(1.7-7.5)^{+}$ \\
\hline Ozaki et al., 1996 [24] & $\mathrm{R}$ & 21 & $51(25-71)$ & $67 \%$ & $12(5-22)$ \\
\hline Staals et al., 2006 [25] & $\mathrm{R}$ & $123^{*}$ & $59(24-83)$ & $54 \%$ & $2.8(0-17)$ \\
\hline van Maldegem et al., 2014 [26] & $\mathrm{R}$ & 171 & $53(17-90)$ & $63 \%$ & . \\
\hline
\end{tabular}

* 110 patients with actual follow-up data, $\mathrm{R}=$ retrospective, and ${ }^{+}$surviving patients.

included patients with a variety of different tumor grades. The localizations of the tumors comprise the entire skeleton throughout the different studies (Table 2).

In 10 out of the 13 studies the surgical margin status was determined showing a wide range in the percentages of patients having wide and radical resection (Table 6).

The additional use of chemotherapy and radiotherapy is only registered in, respectively, 9 out of $13(69 \%)$ and 6 out of $13(46 \%)$ studies. Chemotherapy is used in 6 out of the $9(67 \%)$ studies where chemotherapy is mentioned. Radiotherapy is used in 4 out of the $6(67 \%)$ studies where its use is mentioned (Table 5).

\section{Results}

3.1. Survival: General. Overall survival ranged from $21 \%$ to $100 \%$ at the time of follow-up depending on the specific study. Five- and 10 -year survival ranged from $2 \%$ to $100 \%$ and $32 \%$ to $85 \%$, respectively (Table 3 ). Disease-free survival ranged from $30 \%$ to $89 \%$ and the local recurrence rate ranged from $6.2 \%$ to $35 \%$. In the 5 studies reporting the metastasis rate the rate ranges from $0 \%$ to $38 \%$ (Table 4 ).

3.2. Survival: Grades 1, 2, and 3 and Dedifferentiated Chondrosarcoma. The reported 5-year survival for grade 1 chondrosarcoma ranged from $82 \%$ to $99 \%$. The 10 -year survival ranged from $89 \%$ to $95 \%$. The 5 -year survival for grade 2 chondrosarcoma ranged from $63 \%$ to $92 \%$. The 10 -year survival ranged from $58 \%$ to $86 \%$. The 5 -year survival for grade 3 chondrosarcoma ranged from $0 \%$ to $77 \%$. The lowest $(0 \%)$ survival was displayed in a study looking at a very small subgroup of patients treated with an intralesional resection. The 10 -year survival ranged from $0 \%$ to $55 \%$. The 5 -year survival for dedifferentiated chondrosarcoma was $24 \%$ as reported in 1 study (Table 3 ).
3.3. Prognostic Factors. In 7 of the included studies prognostic factors for overall survival were reported. Cho et al. found no difference in event-free survival between curettage in combination with subsequent treatment versus standard treatment of wide excision $(p=0.16)$ in their cohort of grade 2 chondrosarcoma of the extremities [18]. Donati et al. compared survival of central with peripheral chondrosarcoma and found a difference in survival in their cohort of pelvis tumors $(p=0.00093)$ as did Gitelis et al. at 5-year $(p<0.001)$ and 10-year $(p<0.001)$ as well as in total disease-free survival $(p<0.005)$ between central and peripheral chondrosarcoma $[21,22]$.

Andreou et al., Angelini et al., and Staals et al. investigated multiple potential prognostic factors $[15,16,25]$ as summarized in Table 7. The main significant poor prognostic factors Andreou et al. and/or Angelini et al. reported were larger tumor volume, higher grade and distant metastasis, and a worse prognosis for axial located tumors (including the pelvis) compared to in the extremity located tumors. Worst prognosis for a pathologic fracture and supportive care in comparison with multidisciplinary treatment (chemotherapy, radiotherapy, and further surgery) were reported as well. Staals et al. most prominent findings were the significant impact of Stage 3 lesions versus, respectively, Stages $2 \mathrm{a}$ and $2 \mathrm{~b}$ lesions and the poor prognostic value of a higher percentage of dedifferentiated component within the tumor [25]. van Maldegem et al. show in unresectable chondrosarcoma a survival benefit for the use of chemotherapy compared to not using systemic treatment. When interpreting these results, the large heterogeneity in the treatment groups should be accounted for. In addition they show significant impact of solely unresectable disease compared to unresectable disease in combination with the presence of metastasis. Finally they showed that an age younger than 40 and grade 2 tumors have a better survival [26] (Table 7). 


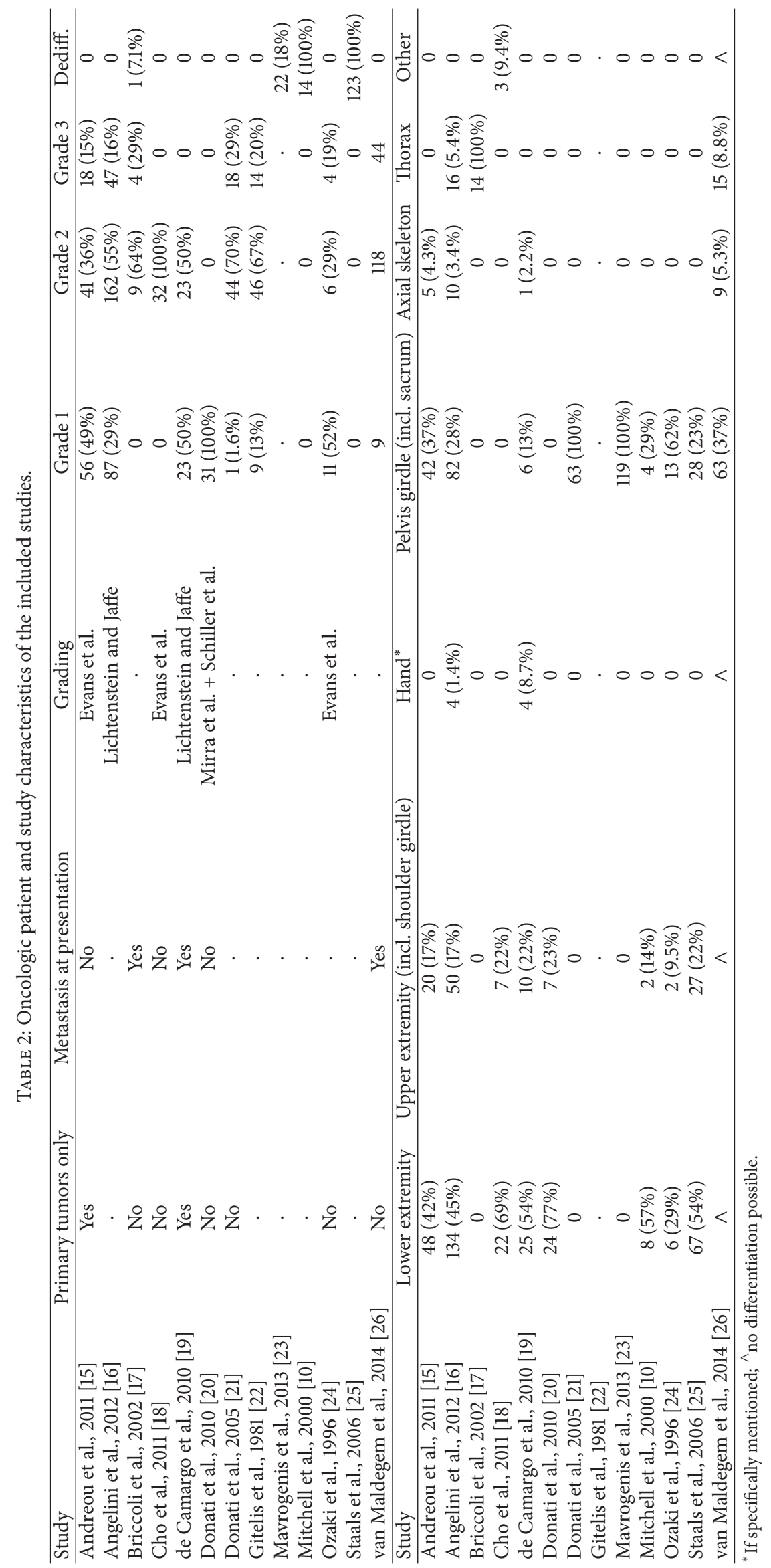


TABLE 3: Oncologic outcome, survival.

\begin{tabular}{|c|c|c|c|c|c|}
\hline Study & $\begin{array}{c}\text { Overall } \\
\text { survival }\end{array}$ & $\begin{array}{c}5 y \\
\text { survival }\end{array}$ & $\begin{array}{c}10 \mathrm{y} \\
\text { survival }\end{array}$ & $\begin{array}{c}\text { Grade } 1 \\
5 \text { y survival }\end{array}$ & $\begin{array}{c}\text { Grade } 1 \\
10 \text { y survival }\end{array}$ \\
\hline Andreou et al., 2011 [15] & $63 \%$ & $72 \%$ & $69 \%$ & $89 \%$ & $89 \%$ \\
\hline Angelini et al., 2012 [16] & $84 \%$ & $92 \%$ & $84 \%$ & $99 \%$ & $95 \%$ \\
\hline Briccoli et al., 2002 [17] & $86 \%$ & . & . & . & . \\
\hline Cho et al., 2011 [18] & $84 \%$ & . & $85 \%^{\wedge}$ & . & . \\
\hline de Camargo et al., 2010 [19] & $94 \%^{\wedge \wedge}$ & . & . & . & . \\
\hline Donati et al., 2010 [20] & $100 \%$ & $100 \%$ & . & . & . \\
\hline Donati et al., 2005 [21] & $73 \%$ & . & . & . & . \\
\hline Gitelis et al., 1981 [22] & . & $49 \%$ & $32 \%$ & . & . \\
\hline Mavrogenis et al., 2013 [23] & . & $80 \%{ }^{*}$ & $65 \%^{*}$ & . & . \\
\hline Mitchell et al., 2000 [10] & $21 \%$ & . & . & . & . \\
\hline Ozaki et al., 1996 [24] & $57 \%$ & . & . & $82 \%$ & . \\
\hline Staals et al., 2006 [25] & $24 \%$ & $24 \%$ & . & . & . \\
\hline van Maldegem et al., 2014 [26] & . & $2 \%$ & . & . & . \\
\hline Study & $\begin{array}{c}\text { Grade } 2 \\
5 \text { y survival }\end{array}$ & $\begin{array}{c}\text { Grade } 2 \\
10 \text { y survival }\end{array}$ & $\begin{array}{c}\text { Grade } 3 \\
5 \text { y survival }\end{array}$ & $\begin{array}{c}\text { Grade } 3 \\
10 \text { y survival }\end{array}$ & $\begin{array}{c}\text { Dedifferentiated } \\
5 \text { y survival }\end{array}$ \\
\hline Andreou et al., 2011 [15] & $63 \%$ & $58 \%$ & $39 \%$ & $33 \%$ & . \\
\hline Angelini et al., 2012 [16] & $92 \%$ & $86 \%$ & $77 \%$ & $55 \%$ & . \\
\hline Briccoli et al., 2002 [17] & . & . & $50 \%$ & . & . \\
\hline Cho et al., 2011 [18] & . & $85 \%^{\wedge}$ & . & . & . \\
\hline de Camargo et al., 2010 [19] & . & . & . & . & . \\
\hline Donati et al., 2010 [20] & . & . & . & . & . \\
\hline Donati et al., 2005 [21] & . & . & . & . & . \\
\hline Gitelis et al., 1981 [22] & . & . & . & . & . \\
\hline Mavrogenis et al., 2013 [23] & . & . & . & . & . \\
\hline Mitchell et al., 2000 [10] & . & . & . & . & . \\
\hline Ozaki et al., 1996 [24] & $67 \%$ & . & $0 \%$ & . & . \\
\hline Staals et al., 2006 [25] & . & . & . & . & $24 \%$ \\
\hline van Maldegem et al., 2014 [26] & . & . & . & . & . \\
\hline
\end{tabular}

${ }^{*}$ Extracted from Kaplan Meier curve, ${ }^{\wedge} 43 / 46=93 \%$, and ${ }^{\wedge}$ discrepancy calculation and manuscript.

TABLE 4: Oncologic outcome, survival.

\begin{tabular}{|c|c|c|c|c|c|c|}
\hline Study & $\begin{array}{c}\text { Disease-free } \\
\text { survival }\end{array}$ & $\begin{array}{c}\text { No evidence } \\
\text { of disease }\end{array}$ & $\begin{array}{c}\text { No evidence of } \\
\text { disease }\end{array}$ & Alive with disease & $\begin{array}{l}\text { Dead of } \\
\text { disease }\end{array}$ & $\begin{array}{c}\text { Dead of other } \\
\text { causes }\end{array}$ \\
\hline Andreou et al., 2011 [15] & $63 \%$ & $73(63 \%)$ & 0 & 0 & $38^{*}(33 \%)$ & $4(3.5 \%)$ \\
\hline Angelini et al., 2012 [16] & $79 \%$ & $201(68 \%)$ & $33(11 \%)$ & $15(5.1 \%)$ & $35(12 \%)$ & $12(4.1 \%)$ \\
\hline Briccoli et al., 2002 [17] & $71 \%$ & $10(71 \%)$ & . & $2(14 \%)$ & $1(7.1 \%)$ & $1(7.1 \%)$ \\
\hline Cho et al., 2011 [18] & $75 \%$ & $24(75 \%)$ & $2(6.3 \%)$ & $3(9.4 \%)$ & $5(16 \%)$ & 0 \\
\hline de Camargo et al., 2010 [19] & $89 \%$ & $\cdot$ & . & $6(13 \%)$ & $3(7 \%)$ & 0 \\
\hline Donati et al., 2010 [20] & . & $29(94 \%)$ & $2(6.5 \%)$ & 0 & 0 & 0 \\
\hline Donati et al., 2005 [21] & . & . & . & . & . & . \\
\hline Gitelis et al., 1981 [22] & $30 \%$ & . & . & . & . & . \\
\hline Mavrogenis et al., 2013 [23] & . & . & . & . & . & . \\
\hline Mitchell et al., 2000 [10] & . & . & . & . & . & . \\
\hline Ozaki et al., 1996 [24] & $62 \%$ & $4(19 \%)$ & $9(43 \%)$ & 0 & $7(33 \%)$ & $1(4.8 \%)$ \\
\hline Staals et al., 2006 [25] & . & . & . & . & $84(76 \%)$ & . \\
\hline van Maldegem et al., 2014 [26] & . & . & . & . & . & . \\
\hline
\end{tabular}

${ }^{*}$ Including 6 treatment related deaths. 
TABLE 5

\begin{tabular}{|c|c|c|c|c|c|c|}
\hline Study & Local recurrence & $\begin{array}{c}\text { Time to local } \\
\text { recurrence } \\
\text { (months) }\end{array}$ & Metastasis & $\begin{array}{c}\text { Time to } \\
\text { metastasis } \\
\text { (months) }\end{array}$ & Chemotherapy & Radiation \\
\hline Andreou et al., 2011 [15] & $38(33 \%)$ & $21(2-96)$ & $30(26 \%)$ & $27(2-141)$ & Used & Used \\
\hline Angelini et al., 2012 [16] & $50(17 \%)$ & . & $41(14 \%)$ & . & Not used & Not used \\
\hline Briccoli et al., 2002 [17] & $6(43 \%)$ & . & . & . & Used & . \\
\hline Cho et al., 2011 [18] & $2(6.2 \%)$ & . & $10(31 \%)$ & $49(7-181)^{*}$ & . & . \\
\hline de Camargo et al., 2010 [19] & $16(35 \%)$ & $24(9-46)$ & . & . & Not used & Not used \\
\hline Donati et al., 2010 [20] & $2(6.5 \%)$ & $31(31-31)$ & 0 & . & . & . \\
\hline Donati et al., 2005 [21] & $15(24 \%)$ & . & . & . & . & . \\
\hline Gitelis et al., 1981 [22] & $22(32 \%)$ & . & $26(38 \%)$ & . & . & . \\
\hline Mavrogenis et al., 2013 [23] & . & . & . & . & Used & . \\
\hline Mitchell et al., 2000 [10] & . & . & . & . & Used & Used \\
\hline Ozaki et al., 1996 [24] & . & . & . & . & Not used & Used \\
\hline Staals et al., 2006 [25] & . & . & . & . & Used & . \\
\hline van Maldegem et al., 2014 [26] & . & . & . & . & Used & Used \\
\hline
\end{tabular}

${ }^{*}$ Different numbers calculable in paper.

TABLE 6

\begin{tabular}{lcc}
\hline Study & $\begin{array}{c}\text { Inadequate surgical margins } \\
\text { Enneking: intralesional or marginal }\end{array}$ & Wide and radical margin \\
\hline Andreou et al., 2011 [15] & $21(18 \%)$ & $94(82 \%)$ \\
Angelini et al., $2012[16]$ & $74(25 \%)$ & $222(75 \%)$ \\
Briccoli et al., $2002[17]$ & $3(21 \%)$ & $11(79 \%)$ \\
Cho et al., 2011 [18] & $7(22 \%)$ & $25(78 \%)$ \\
de Camargo et al., 2010 [19] & $25(54 \%)$ & $18(39 \%)$ \\
Donati et al., $2010[20]$ & $17(55 \%)$ & $14(45 \%)$ \\
Donati et al., $2005[21]$ & $17(27 \%)$ & $46(73 \%)$ \\
Gitelis et al., $1981[22]$ & $37(54 \%)$ & $32(46 \%)$ \\
Mavrogenis et al., 2013 [23] & $\cdot$ & $\cdot$ \\
Mitchell et al., 2000 [10] & $\cdot$ &. \\
Ozaki et al., 1996 [24] & $21(100 \%)$ & 0 \\
Staals et al., 2006 [25] & $\cdot$ &. \\
van Maldegem et al., 2014 [26] & $52(30 \%)^{*}$ & $87(51 \%)^{*}$ \\
\hline
\end{tabular}

*Initial surgery.

\section{Discussion and Conclusions}

The results of our study show that the prognosis of central chondrosarcoma is fairly good for the low histological grade tumors with a 5- and 10-year survival of over $80 \%$. Highgrade chondrosarcoma and the highly lethal dedifferentiated chondrosarcoma have a poor prognosis with lower survival rates. The main negative prognostic factors for overall survival displayed in this review are a higher tumor grade and an axial/pelvis location of the tumor for the conventional chondrosarcoma. The percentage of dedifferentiated component within dedifferentiated chondrosarcoma has significant influence on disease-free survival of these tumors.

This review should be interpreted with its limitations in mind. First of all there are only limited studies in literature that describe solely central chondrosarcoma (or where the central chondrosarcomas are identifiable). The included studies are all retrospective and, even though we used strict inclusion criteria, have a large heterogeneity between patients and treatments. The heterogeneity in histologic type of grading used to evaluate the tumors, the variability in the use of chemo- and radiotherapy, and the differences in the presence of inadequate surgical margins might all have influenced our study's main outcomes. Second limitation is the likely overlap in patient population that can be explained by the centralization of care in large institutions due to the low incidence of primary orthopaedic tumors in general populations. This might introduce a bias and might amplify the experience of a single (experienced) center. Finally there is a large heterogeneity in the outcome measures, partially explained by differences in follow-up time, which makes the direct comparison and getting a general overview of the 
TABle 7: Prognostic factors.

\begin{tabular}{|c|c|}
\hline \multicolumn{2}{|l|}{ Andreou et al. [15] } \\
\hline \multicolumn{2}{|l|}{ Overall survival } \\
\hline Variable (bivariate analysis) & p value \\
\hline Sex & $p=0.6$ \\
\hline Age (higher) & $p=0.04$ \\
\hline Extremity versus axial + pelvis & $p=0.002$ \\
\hline Tumor volume (0-100 cc vs. $>100 \mathrm{cc})$ & $p<0.001$ \\
\hline Grade tumor & $p<0.001$ \\
\hline Local recurrences & $p<0.001$ \\
\hline Distant metastasis & $p<0.001$ \\
\hline Surgical margins & $p=0.9$ \\
\hline \multicolumn{2}{|l|}{ Type of surgery } \\
\hline Low grade: ablative versus limb-sparing & $p=0.7$ \\
\hline High grade: ablative versus limb-sparing & $p=0.1$ \\
\hline Pathologic fracture & $p=0.002$ \\
\hline ACJCC & $p<0.001$ \\
\hline Multi disc. versus support. care & $p=0.001$ \\
\hline \multicolumn{2}{|l|}{ Variable (multivariate analysis) } \\
\hline High grade: $R R=5$ & $p<0.001$ \\
\hline Axial + pelvis: $\mathrm{RR}=2$ & $p=0.04$ \\
\hline \multicolumn{2}{|l|}{ Staals et al. [25] } \\
\hline \multicolumn{2}{|l|}{ Disease-free survival } \\
\hline Variable (bivariate analysis) & p value \\
\hline Gender & NS \\
\hline Age & NS \\
\hline Duration of symptoms & NS \\
\hline Lesion size & NS \\
\hline Anatomic location & NS \\
\hline Stage 3 versus Stage $2 a$ & $p=0.003$ \\
\hline Stage 3 versus Stage $2 b$ & $p<0.00005$ \\
\hline Stage $2 \mathrm{a}$ versus Stage $2 \mathrm{~b}$ & $p=0.27$ \\
\hline Histologic subtype, MFH versus OS & $p=0.046$ \\
\hline Histologic subtype, MFH versus fibr. sarc. & $p=0.08$ \\
\hline Histologic subtype, OS versus fibr. sarc. & $p=0.96$ \\
\hline Grade 3DD versus grade 4DD & $p=0.10$ \\
\hline Percentage of DD component & $p=0.0102$ \\
\hline $\begin{array}{l}\text { Percentage of DD component, }>50 \% \text { versus } \\
<50 \%\end{array}$ & $p<0.00005$ \\
\hline Limb-sparing versus resection & $p=0.08$ \\
\hline Surgery versus surgery + chemotherapy & $p=0.88$ \\
\hline \multicolumn{2}{|l|}{$\begin{array}{l}\text { Variable (multivariate analysis, overall } \\
\text { survival) }\end{array}$} \\
\hline Percentage of DD component & $p=0.0102$ \\
\hline \multicolumn{2}{|l|}{ Angelini et al. [16] } \\
\hline \multicolumn{2}{|l|}{ Overall survival } \\
\hline Variable (bivariate analysis) & p value \\
\hline G1: wide versus intralesional & $p=0.495$ \\
\hline G1: extremity versus trunk & $p=0.595$ \\
\hline G2: wide versus intralesional & $p=0.948$ \\
\hline G2: extremity versus trunk & $p=0.589$ \\
\hline
\end{tabular}

TABLE 7: Continued.

\begin{tabular}{|c|c|}
\hline G2: resect. versus amputation & $p=0.496$ \\
\hline G3: extremity versus trunk & $p=0.039$ \\
\hline G3: resect. versus amputation & $p=0.051$ \\
\hline \multicolumn{2}{|l|}{ Variable (multivariate analysis) } \\
\hline G3: resect. versus amputation & $p=0.0943$ \\
\hline G3: extr. versus trunk & $p=0.0889$ \\
\hline \multicolumn{2}{|l|}{ van Maldegem et al. [26] } \\
\hline \multicolumn{2}{|c|}{ Overall survival from the day of unresectability } \\
\hline Variable (bivariate analysis) & $p$ value \\
\hline $\begin{array}{l}\text { Only local unresectable disease versus local } \\
\text { unresectable disease + metastasis }\end{array}$ & $p=0.0014$ \\
\hline Age ( $<40$ years $)$ & $p=0.001$ \\
\hline Grade II tumors & $p=0.022$ \\
\hline Sex & NS \\
\hline Site & NS \\
\hline $\begin{array}{l}\text { Resectable versus nonresectable disease at } \\
\text { primary diagnosis }\end{array}$ & NS \\
\hline Systemic treatment & $p<0.0487$ \\
\hline
\end{tabular}

$\mathrm{RR}=$ Relative Risk, $\mathrm{G}=$ grade, $\mathrm{MFH}=$ malignant fibrohistocytoma, $\mathrm{OS}=$ osteosarcoma, and $\mathrm{DD}=$ dedifferentiated.

included studies challenging. This is, for example, displayed in the wide ranges in survival statistics. The grade 3 tumors have a range of $0-77 \%$-year survival. Most likely this difference is caused by comparing a small subgroup of intralesional treated tumors with the results from a highly specialized center. Also significant interobserver variability in pathologists' histologic grading is known to be present in these types of tumors [27]. This might also directly influence the reported outcomes.

Remarkably in contrast to reports in literature on chondrosarcoma $[28,29]$, surgical margins were not identified as independent predictor of survival in this review. However, as stated by Andreou et al. as well, in multivariable analysis Lee et al. showed only a small effect of surgical margin status on survival and Fiorenza et al. were not able to determine the effect when accounting for confounders factors [15]. Caution is needed when interpreting these conclusions and their potential consequences in practice. Relative small retrospective studies with a large heterogeneity of patients might be the cause of the inability to identify, in oncology commonly accepted, prognostic factors such as wide surgical margins.

Our study points out that there is a need for prospective and comparative studies identifying factors and treatments influencing the survival of patients suffering from central chondrosarcoma. More evidence from high quality research might eventually lead to a more evidence-based foundation of treatments while preventing abundant exposure of patients to potentially harmful therapies such as radiation and chemotherapy. Further centralization of care for patients with relatively rare diseases would be desirable from a patient's point of view but might also generate opportunities for researchers to set up prospective and comparative studies. To improve survival in central chondrosarcoma patients, 
Table 8

(a)

\begin{tabular}{|c|c|c|c|c|c|}
\hline \multirow{2}{*}{$\begin{array}{l}\text { Author, year } \\
\text { Andreou et al., } 2011 \text { [15] }\end{array}$} & $\begin{array}{c}\text { Study participation: } \\
\text { Dates of researched period stated } \\
\text { Clearly defined patient sample, } \\
\text { assembled at a common point in } \\
\text { course of the disease }\end{array}$ & \multicolumn{2}{|c|}{$\begin{array}{l}\text { Study attrition: } \\
\text { Sufficiently long and complete } \\
\text { follow-up ( } \geq 2 \text { years and } \geq 80 \% \text { ) } \\
\text { Explaining reasons for patients } \\
\text { being lost to follow-up }\end{array}$} & \multicolumn{2}{|c|}{$\begin{array}{c}\text { Confounding } \\
\text { measurement: } \\
\text { Defined and comparable } \\
\text { treatment for patients }\end{array}$} \\
\hline & 1 & & & & $\begin{array}{l}\text { surgery } \\
\text { oned }\end{array}$ \\
\hline Angelini et al., 2012 [16] & 1 & & & & $\begin{array}{l}\text { surgery } \\
\text { oned }\end{array}$ \\
\hline Briccoli et al., 2002 [17] & 1 & & & & $\begin{array}{l}\text { surgery } \\
\text { oned }\end{array}$ \\
\hline Cho et al., 2011 [18] & 1 & & & & $\begin{array}{l}\text { surgery } \\
\text { oned }\end{array}$ \\
\hline de Camargo et al., 2010 [19] & 1 & & & & $\begin{array}{l}\text { surgery } \\
\text { oned }\end{array}$ \\
\hline Donati et al., 2010 [20] & 1 & & & & $\begin{array}{l}\text { surgery } \\
\text { oned }\end{array}$ \\
\hline Donati et al., 2005 [21] & 1 & & & & $\begin{array}{l}\text { surgery } \\
\text { oned }\end{array}$ \\
\hline Gitelis et al., 1981 [22] & 1 & & & & $\begin{array}{l}\text { surgery } \\
\text { oned }\end{array}$ \\
\hline Mavrogenis et al., 2013 [23] & 1 & & & & $\begin{array}{l}\text { surgery } \\
\text { oned }\end{array}$ \\
\hline Mitchell et al., 2000 [10] & 1 & & & & $\begin{array}{l}\text { surgery } \\
\text { oned }\end{array}$ \\
\hline Ozaki et al., 1996 [24] & 1 & & & & $\begin{array}{l}\text { surgery } \\
\text { oned }\end{array}$ \\
\hline Staals et al., 2006 [25] & 1 & & & & $\begin{array}{l}\text { surgery } \\
\text { oned }\end{array}$ \\
\hline van Maldegem et al., 2014 [26] & 1 & & & & $\begin{array}{l}\text { surgery } \\
\text { oned }\end{array}$ \\
\hline Author, year & $\begin{array}{r}\text { Analysis } \\
\text { Valid statistical anal } \\
\text { Multivariable analy }\end{array}$ & $\begin{array}{l}\text { ris is done } \\
\text { sis is done }\end{array}$ & $\begin{array}{l}\text { Popula } \\
\text { (no ove }\end{array}$ & $\begin{array}{l}\text { on: } \\
\text { lap) }\end{array}$ & Disclosure \\
\hline Andreou et al., 2011 [15] & 1 & & 1 & & 1 \\
\hline Angelini et al., 2012 [16] & 1 & & 0 & & 1 \\
\hline Briccoli et al., 2002 [17] & 0 & & 0 & & 0 \\
\hline Cho et al., 2011 [18] & 0 & & 1 & & 1 \\
\hline de Camargo et al., 2010 [19] & 0 & & 1 & & 1 \\
\hline Donati et al., 2010 [20] & 0 & & 0 & & 1 \\
\hline Donati et al., 2005 [21] & 1 , but not on centr & 1 survival & 0 & & 1 \\
\hline Gitelis et al., 1981 [22] & 0 & & 0 & & 0 \\
\hline Mavrogenis et al., 2013 [23] & 1 & & 0 & & 1 \\
\hline Mitchell et al., 2000 [10] & 0 & & 1 & & 1 \\
\hline Ozaki et al., 1996 [24] & 0 & & 1 & & 0 \\
\hline Staals et al., 2006 [25] & 0 & & 0 & & 0 \\
\hline van Maldegem et al., 2014 [26] & 0 & & 0 & & 1 \\
\hline
\end{tabular}


(c)

Author, year

Andreou et al., 2011 [15]

Angelini et al., 2012 [16]

Briccoli et al., 2002 [17]

Cho et al., 2011 [18]

de Camargo et al., 2010 [19]

Donati et al., 2010 [20]

Donati et al., 2005 [21]

Gitelis et al., 1981 [22]

Mavrogenis et al., 2013 [23]

Mitchell et al., 2000 [10]

Ozaki et al., 1996 [24]

Staals et al., 2006 [25]

van Maldegem et al., 2014 [26]
Prognostic factor measurement: Clear definition and valid assessment of prognostic factors
Outcome measurement:

Well defined outcome parameters (survival: overall, metastatic-free,

$\begin{array}{ll}1 & 1 \\ 1 & 1 \\ 0 & 0 \\ 1 & 1 \\ 1 & 1 \\ 1 & 1 \\ 1 & 0 \\ 1 & 0 \\ 1 & 1 \\ 1 & 1 \\ 1 & 0 \\ 1 & 1 \\ 1 & 1 \\ (1) & 1\end{array}$

\begin{tabular}{|c|c|c|}
\hline Author, year & FU $>1$ year & Level of evidence I-IV \\
\hline Andreou et al., 2011 [15] & 1 & 4, prognostic \\
\hline Angelini et al., 2012 [16] & 1 & 4 , prognostic \\
\hline Briccoli et al., 2002 [17] & 0 & 4 , prognostic \\
\hline Cho et al., 2011 [18] & 1 & 3 , therapeutic \\
\hline de Camargo et al., 2010 [19] & 1 & 4, prognostic \\
\hline Donati et al., 2010 [20] & 1 & 2 , prognostic \\
\hline Donati et al., 2005 [21] & 1 & 4 , prognostic \\
\hline Gitelis et al., 1981 [22] & 1 & 4 , prognostic \\
\hline Mavrogenis et al., 2013 [23] & 1 & 4, prognostic \\
\hline Mitchell et al., 2000 [10] & 1 & 4, prognostic \\
\hline Ozaki et al., 1996 [24] & 1 & 4 , prognostic \\
\hline Staals et al., 2006 [25] & 0 & 4 , prognostic \\
\hline van Maldegem et al., 2014 [26] & 1 & 4 , prognostic \\
\hline \multicolumn{3}{|l|}{ 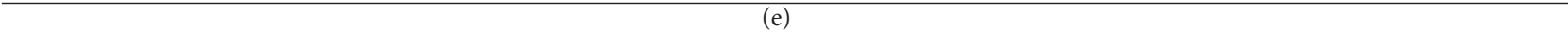 } \\
\hline Author, year & $\begin{array}{c}\text { Confounding measurement } \\
\text { Defined and comparable treatment for } \\
\text { patients }\end{array}$ & Baseline \\
\hline Andreou et al., 2011 [15] & 1 , types of surgery mentioned & 0 \\
\hline Angelini et al., 2012 [16] & 1 , types of surgery mentioned & 0 \\
\hline Briccoli et al., 2002 [17] & 1 , types of surgery mentioned & 1 \\
\hline Cho et al., 2011 [18] & 1 , types of surgery mentioned & 0 \\
\hline de Camargo et al., 2010 [19] & 1 , types of surgery mentioned & 0 \\
\hline Donati et al., 2010 [20] & 1 , types of surgery mentioned & 1 \\
\hline Donati et al., 2005 [21] & 1 , types of surgery mentioned & 0 \\
\hline Gitelis et al., 1981 [22] & 1 , types of surgery mentioned & 1 \\
\hline Mavrogenis et al., 2013 [23] & 1 , types of surgery mentioned & 0 \\
\hline Mitchell et al., 2000 [10] & 1 , types of surgery mentioned & 1 \\
\hline Ozaki et al., 1996 [24] & 1 , types of surgery mentioned & 1 \\
\hline Staals et al., 2006 [25] & 1 , types of surgery mentioned & 0 \\
\hline van Maldegem et al., 2014 [26] & 1 , types of surgery mentioned & 1 \\
\hline
\end{tabular}


(f)

\begin{tabular}{lc}
\hline Author, year & Disclosure \\
\hline Andreou et al., 2011 [15] & 1 \\
Angelini et al., 2012 [16] & 1 \\
Briccoli et al., 2002 [17] & 0 \\
Cho et al., 2011 [18] & 1 \\
de Camargo et al., 2010 [19] & 1 \\
Donati et al., 2010 [20] & 1 \\
Donati et al., 2005 [21] & 1 \\
Gitelis et al., 1981 [22] & 0 \\
Mavrogenis et al., 2013 [23] & 1 \\
Mitchell et al., 2000 [10] & 1 \\
Ozaki et al., 1996 [24] & 0 \\
Staals et al., 2006 [25] & 0 \\
van Maldegem et al., 2014 [26] & 1 \\
\hline
\end{tabular}

the high-grade chondrosarcoma and the dedifferentiated chondrosarcoma seem to be good candidates for future studies exploring better treatments options due to their poor prognosis.

\section{Appendix}

See Table 8.

\section{Conflict of Interests}

The authors declare that there is no conflict of interests regarding the publication of this paper.

\section{Authors' Contribution}

All authors have made substantial contributions to all of the following: (1) the conception and design of the study, or acquisition of data, or analysis and interpretation of data, (2) drafting the paper or revising it critically for important intellectual content, and (3) final approval of the version to be submitted.

\section{References}

[1] P. B. Hogendoorn, J. M. Bovee, and G. P. Nielsen, "Chondrosarcoma (grades I-III), including primary and secondary variants and periosteal chondrosarcoma," in World Health Organization Classification of Tumours of Soft Tissue and Bone, C. D. M. Fletcher, J. A. Bridge, P. C. W. Hogendoorn, and F. Mertens, Eds., vol. 5, p. 264, IARC, Lyon, France, 2013.

[2] H. D. Dorfman and B. Czerniak, "Bone cancers," Cancer, vol. 75, no. 1, supplement, pp. 203-210, 1995.

[3] T. A. Damron, W. G. Ward, and A. Stewart, "Osteosarcoma, chondrosarcoma, and Ewing's sarcoma: national cancer data base report," Clinical Orthopaedics and Related Research, vol. 459, pp. 40-47, 2007.

[4] H. L. Evans, A. G. Ayala, and M. M. Romsdahl, "Prognostic factors in chondrosarcoma of bone: a clinicopathologic analysis with emphasis on histologic grading," Cancer, vol. 40, no. 2, pp. 818-831, 1977.
[5] A. Y. Giuffrida, J. E. Burgueno, L. G. Koniaris, J. C. Gutierrez, R. Duncan, and S. P. Scully, "Chondrosarcoma in the United States (1973 to 2003): an analysis of 2890 cases from the SEER database," The Journal of Bone \& Joint Surgery-American Volume, vol. 91, no. 5, pp. 1063-1072, 2009.

[6] A. R. Ahmed, T.-S. Tan, K. K. Unni, M. S. Collins, D. E. Wenger, and F. H. Sim, "Secondary chondrosarcoma in osteochondroma: report of 107 patients," Clinical Orthopaedics and Related Research, no. 411, pp. 193-206, 2003.

[7] A. Italiano, O. Mir, A. Cioffi et al., "Advanced chondrosarcomas: role of chemotherapy and survival," Annals of Oncology, vol. 24, no. 11, Article ID mdt374, pp. 2916-2922, 2013.

[8] F. Moussavi-Harami, A. Mollano, J. A. Martin et al., "Intrinsic radiation resistance in human chondrosarcoma cells," Biochemical and Biophysical Research Communications, vol. 346, no. 2, pp. 379-385, 2006.

[9] S. Kawaguchi, I. Weiss, P. P. Lin, W. W. Huh, and V. O. Lewis, "Radiation therapy is associated with fewer recurrences in mesenchymal chondrosarcoma," Clinical Orthopaedics and Related Research, vol. 472, no. 3, pp. 856-864, 2014.

[10] A. D. Mitchell, K. Ayoub, D. C. Mangham, R. J. Grimer, S. R. Carter, and R. M. Tillman, "Experience in the treatment of dedifferentiated chondrosarcoma," The Journal of Bone and Joint Surgery-British Volume, vol. 82, no. 1, pp. 55-61, 2000.

[11] E. L. Staals, P. Bacchini, M. Mercuri, and F. Bertoni, "Dedifferentiated chondrosarcomas arising in preexisting osteochondromas," The Journal of Bone \& Joint Surgery-American Volume, vol. 89, no. 5, pp. 987-993, 2007.

[12] I. D. Dickey, P. S. Rose, B. Fuchs et al., "Dedifferentiated chondrosarcoma: the role of chemotherapy with updated outcomes," The Journal of Bone \& Joint Surgery-American Volume, vol. 86, no. 11, pp. 2412-2418, 2004.

[13] R. J. Grimer, G. Gosheger, A. Taminiau et al., "Dedifferentiated chondrosarcoma: prognostic factors and outcome from a European group," European Journal of Cancer, vol. 43, no. 14, pp. 2060-2065, 2007.

[14] D. F. Stroup, J. A. Berlin, S. C. Morton et al., "Meta-analysis of observational studies in epidemiology: a proposal for reporting," Journal of the American Medical Association, vol. 283, no. 15, pp. 2008-2012, 2000. 
[15] D. Andreou, S. Ruppin, S. Fehlberg, D. Pink, M. Werner, and P.-U. Tunn, "Survival and prognostic factors in chondrosarcoma: results in 115 patients with long-term follow-up," Acta Orthopaedica, vol. 82, no. 6, pp. 749-755, 2011.

[16] A. Angelini, G. Guerra, A. F. Mavrogenis, E. Pala, P. Picci, and P. Ruggieri, "Clinical outcome of central conventional chondrosarcoma," Journal of Surgical Oncology, vol. 106, no. 8, pp. 929-937, 2012.

[17] A. Briccoli, M. De Paolis, L. Campanacci et al., "Chondrosarcoma of the chest wall: a clinical analysis," Surgery Today, vol. 32, no. 4, pp. 291-296, 2002.

[18] W. H. Cho, W. S. Song, D.-G. Jeon et al., "Oncologic impact of the curettage of grade 2 central chondrosarcoma of the extremity," Annals of Surgical Oncology, vol. 18, no. 13, pp. 37553761, 2011.

[19] O. P. de Camargo, A. M. Baptista, M. J. Atanásio, and D. R. Waisberg, "Chondrosarcoma of bone: lessons from 46 operated cases in a single institution," Clinical Orthopaedics and Related Research, vol. 468, no. 11, pp. 2969-2975, 2010.

[20] D. Donati, S. Colangeli, M. Colangeli, C. Di Bella, and F. Bertoni, "Surgical treatment of grade I central chondrosarcoma," Clinical Orthopaedics and Related Research, vol. 468, no. 2, pp. 581-589, 2010.

[21] D. Donati, A. El Ghoneimy, F. Bertoni, C. Di Bella, and M. Mercuri, "Surgical treatment and outcome of conventional pelvic chondrosarcoma," The Journal of Bone \& Joint SurgeryBritish Volume, vol. 87, no. 11, pp. 1527-1530, 2005.

[22] S. Gitelis, F. Bertoni, P. Picci, and M. Campanacci, "Chondrosarcoma of bone. The experience at the Istituto Ortopedico Rizzoli," The Journal of Bone and Joint Surgery-American Volume, vol. 63, no. 8, pp. 1248-1257, 1981.

[23] A. F. Mavrogenis, A. Angelini, G. Drago, B. Merlino, and P. Ruggieri, "Survival analysis of patients with chondrosarcomas of the pelvis," Journal of Surgical Oncology, vol. 108, no. 1, pp. 19-27, 2013.

[24] T. Ozaki, N. Lindner, A. Hillmann, R. Rödl, S. Blasius, and W. Winkelmann, "Influence of intralesional surgery on treatment outcome of chondrosarcoma," Cancer, vol. 77, no. 7, pp. 12921297, 1996.

[25] E. L. Staals, P. Bacchini, and F. Bertoni, "Dedifferentiated central chondrosarcoma," Cancer, vol. 106, no. 12, pp. 2682-2691, 2006.

[26] A. M. van Maldegem, H. Gelderblom, E. Palmerini et al., "Outcome of advanced, unresectable conventional central chondrosarcoma," Cancer, vol. 120, no. 20, pp. 3159-3164, 2014.

[27] D. Eefting, Y. M. Schrage, M. J. A. Geirnaerdt et al., "Assessment of interobserver variability and histologic parameters to improve reliability in classification and grading of central cartilaginous tumors," American Journal of Surgical Pathology, vol. 33, no. 1, pp. 50-57, 2009.

[28] F. Fiorenza, A. Abudu, R. J. Grimer et al., "Risk factors for survival and local control in chondrosarcoma of bone," Journal of Bone and Joint Surgery -British Volume, vol. 84, no. 1, pp. 9399, 2002.

[29] F. Y. Lee, H. J. Mankin, G. Fondren et al., "Chondrosarcoma of bone: an assessment of outcome," The Journal of Bone \& Joint Surgery-American Volume, vol. 81, no. 3, pp. 326-338, 1999. 


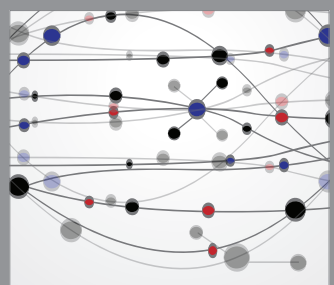

The Scientific World Journal
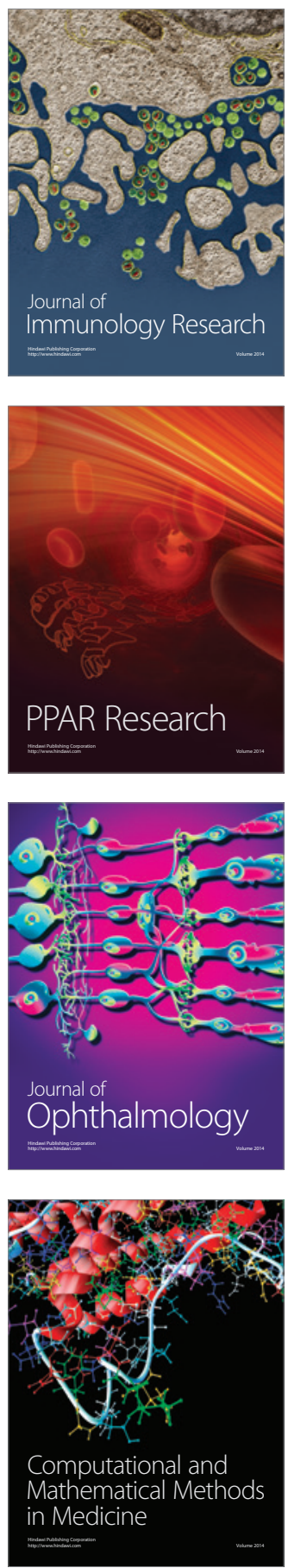

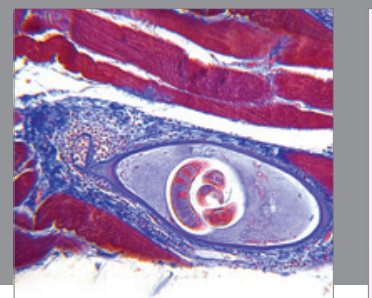

Gastroenterology

Research and Practice
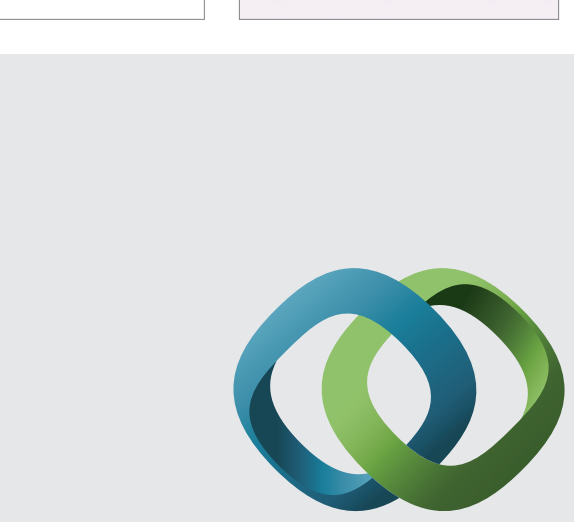

\section{Hindawi}

Submit your manuscripts at

http://www.hindawi.com
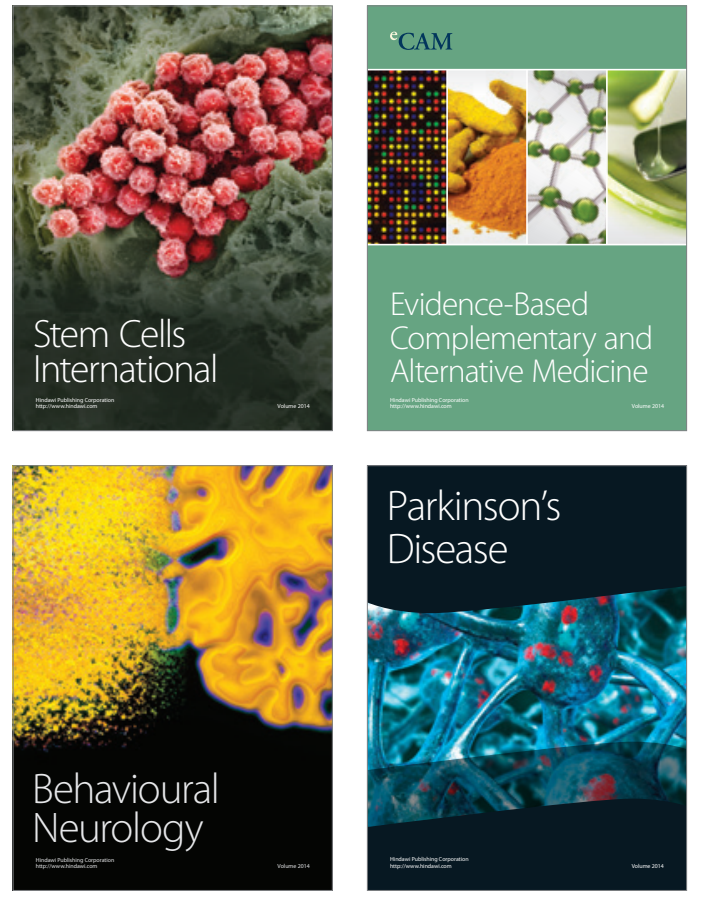
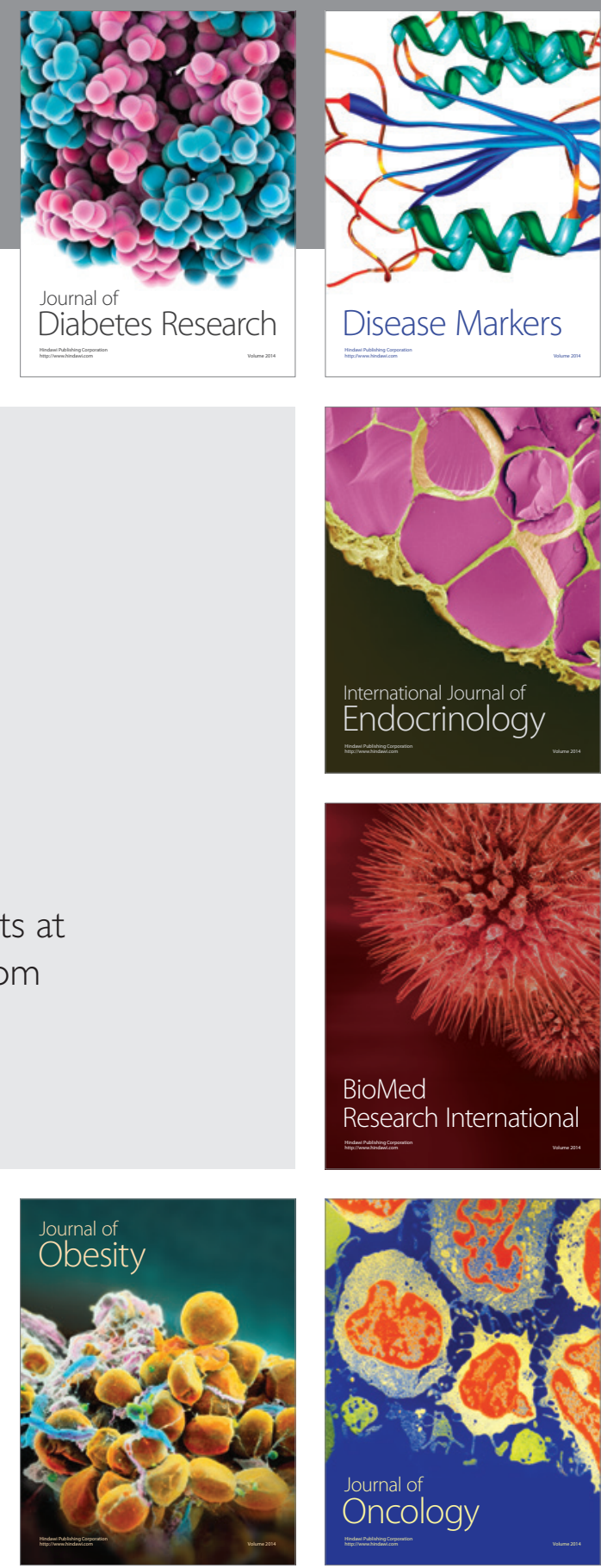

Disease Markers
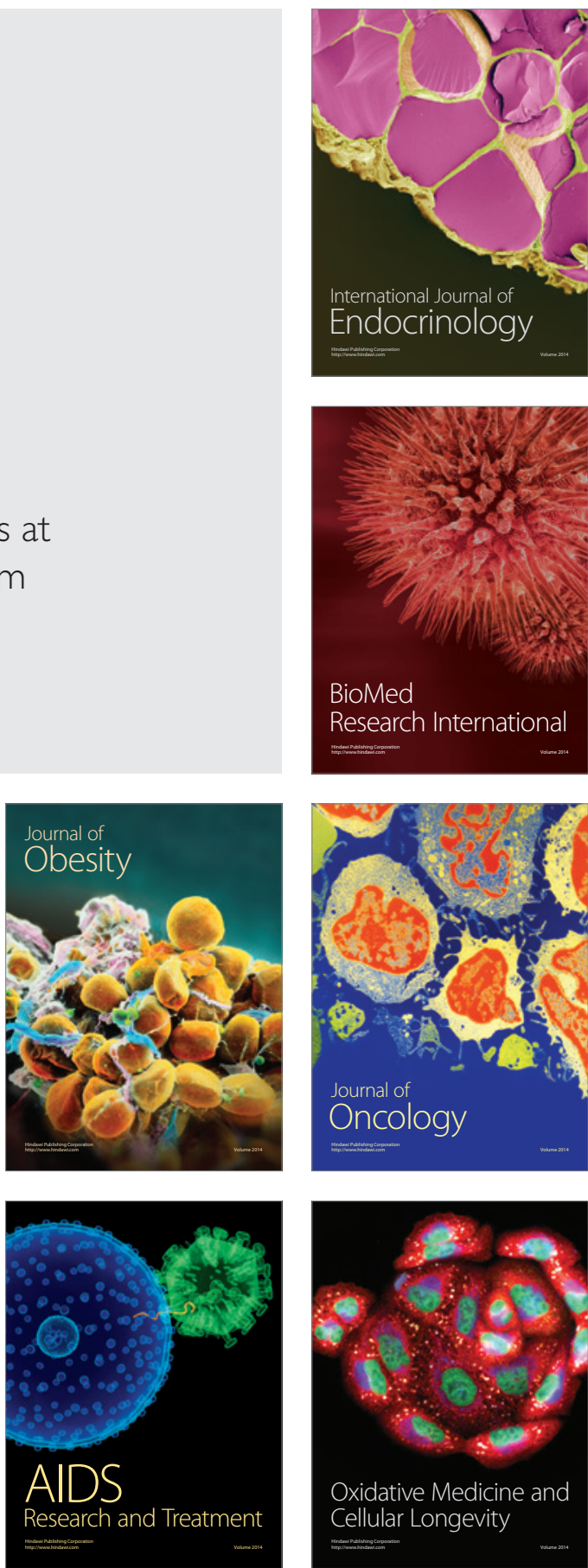